\title{
Non-invasive Water Stress Assessment Methods in Orchards
}

\author{
ATTILA NAGY ${ }^{1}$ AND JÁNOS TAMÁS ${ }^{1}$
}

Institute of Water and Environmental Management, Faculty of Agricultural and Food

Sciences and Environmental Management, University of Debrecen, Debrecen, Hungary

\begin{abstract}
In large orchards up-to-date information is needed on water capacity and possible water stress of the fruit trees. The reason for this is that the physiological reactions against the changing water capacity appear much earlier than the water stress. These physiological changes cannot be observed visually in the early period of water stress. One of the most sensitive indicator of photosynthetic activity, mutations, stress is the chlorophyll content of the vegetation which can be monitored by fotogrammetry. Thus, combining airborne remote sensing technology and reflectance measurements of leaves can be the solution for detection of changing water content. With the use of remote sensing technology large amount of agro-ecologic information can be achieved on sites, such as orchards. The examined intensive apple and the extensive pear orchards, established on sandy soils, are situated in the North Eastern part in Hungary. Apple orchard has microirrigation system. Hyperspectral image was taken by AISA DUAL airborne hyperspectral camera. The full spectra range of this system is $400-2450 \mathrm{~nm}$, which was set to the maximum 498 spectral channels in $2.25 \mathrm{~m}^{2}$ spatial resolution. Parallel to the flight campaign, leaf samples were also taken. Samples of different kind of apple species were analyzed by ALTA II and AvaSpec 2048 hand portable spectrometer. Based on the
\end{abstract}

\footnotetext{
${ }^{1}$ Böszörményi str. 138. 4032 Debrecen, Hungary. e-mail: attilanagy@agr.unideb.hu
} 
hyperspectral image, vegetation indices were also calculated to detect the effect of water stress. Normalized Difference Vegetation Index (NDVI) that is sensitive to changes in biomass and Water Band Index - WBI that is sensitive to changes in canopy water status, were calculated to measure the water supply of the leaves. As a result, the reflectance of 886 and $937 \mathrm{~nm}$ can result more accurate WBI $\left(\mathrm{WBI}=\delta_{886} / \delta_{937}\right)$ in the case of pear trees. The water stressed samples shows higher reflectance in near infra red, and shows lower reflectance in red spectrum.

Keywords: airborne hyperspectral analisys, leaf reflectancy, laboratory reflectancs measurements

\section{Introduction}

It can be forecasted with high probability that in future water will be the determining (hopefully not limiting) factor of food security and environmental safety in the Carpathian Basin (Várallyay, 2002). The limited water resources and the increasing frequency of extreme hydrological events (floods, water-logging, over-moistening and drought) due to the high territorial and temporal variability of atmospheric precipitation; the heterogeneous (micro) relief; and the unfavourable physical/hydrophysical characteristics of soils are pressing to improve agricultural water use efficiency and necessitates an efficient control of soil moisture regime in the Carpathian Basin (Kertész 1995, Jolánkai 2010). Besides droughts, which can be successfully managed by irrigation, occurring surplus water often proves critical in the case of extreme humid years (Juhász, 2008). Consequently, the increase in water use efficiency will be one of the key issues of agricultural production, rural development and environment protection and the control of soil moisture regime will be an imperative task without any other alternatives (Várallyay, 2007). 
Hungary has favuorable agro ecological potential for pomaceous fruit production (Soltész and Szabó 1998). Orchards are relatively not highly water consumer comparison with cereal species. However, to ensure optimal water capacity values calculating breeding season it is the most important risk factor. Therefore in large orchards up-to-date information is needed on water capacity and possible water stress of the fruit trees. The reason for this is that the physiological reactions against the changing water capacity appear much earlier than the water stress. These physiological changes cannot be observed visually in the early period of water stress. Combining airborne remote sensing technology and reflectance measurements of leaves can be the solution for detection of changing water content. Hyper- and multispectral technology is widely used in agriculture and environmental protection, and is appropriate for vegetation analysis (Clark, 1999; Kruse, 2003; Milics et al. 2008; Polder et al. 2001; Sabins, 1997). Vegetation, its chlorophyll content and vegetation indices are good indicators of photosynthetic activity, mutations, stress (Burai et al., 2009), degradation processes occurred in soils, and the state of plant nutrient, and this have a particular high significance in precision agriculture. The chlorophyll content is one of the indicators of the state of health (Burai et al. 2009), which affect the reflectance spectra of the vegetation and the vegetation indices as well. Minimum at the visible spectral range is related to pigments in plant leaves. Chlorophyll absorbs markedly spectral range between $450-670 \mathrm{~nm}$. Healthy vegetation reflects the $40-50 \%$ of the incoming energy between $700-1300 \mathrm{~nm}$ spectral ranges due to the internal structure of the canopy. In this way, the measured reflectance plays an important role in distinguishing different plant species and possible water stress, even if these species are seems to be similar based on visible spectral range (Berke et al., 2004). In reference to this, searching areas referring to early recognizability of plant diseases, mapping of deficiency of nutrients by reflectance spectrum, the singular or association level approach 
of the vegetation in agro-ecological, cropping technologies respect, have to be mentioned (Santoso et al, 2011).

The main aim of this study was to create a new GIS - Remote Sensing data system, which can be the basis of an agri-ecological decision support system.

\section{Materials and methods}

The research was carried out in two orchards in Nyírség meso-region which is situated in North East Hungary. The physical characteristic of the soil is sandy. One of the orchards is a genetic collection of pear (Pyrus communis) species in 2.74 ha, with 1660 possible spaces of pear trees, and the pear orchard is not irrigated. The other orchard is an apple (Malus domestica) orchard in 1 ha with microirrigation system

The leaf samples were collected from different apple species (Gála, Remo, Gála Must, Idared, Jonagold) in integrated and organic cultivation and from different pear species (Napoca, Bajai, Márianosztrai, Republica, Ananas, Summer dean, Kiev Szentendrei császár). Five leaf samples were taken from both the Eastern and Western side of the trees from 120 $\mathrm{cm}$ height. Three trees of each species were examined. Both reflectance and chlorophyll A content were determined. The chlorophyll contents were measured according to the MSZ ISO 10260:1993 patent, using hot ethanol (90\%) for the extraction. The chlorophyll absorbances were detected by Anthelie UV-VIS spectrophotometer at $665 \mathrm{~nm}$ and $750 \mathrm{~nm}$ wavelength. The reflectance spectra were measured by a field portable, ALTA II. Spectrometer at 470, $525,560,585,600,645,700,735,810,880,940 \mathrm{~nm}$ and by a hyperspectral $(1 \mathrm{~nm}$ spectral resolution) AvaSpec 2048 spectrometer within 400 - $1000 \mathrm{~nm}$ wavelength interval. The AvaSpec 2048 system consists of spectrometer, fiber optic and a halogenic light source (Figure 1.). 
Airborne hyperspectral dataset were also taken from the research sites. In 2006, an AISA DUAL airborne hyperspectral camera system were installed and operated in cooperation the University of Debrecen, AGTC, Institute of Water and Environmental Management with the Mechanization Institute of Agricultural Ministry in Gödöllö. The most important parts of the hyperspectral sensors are the spectrographs, which dissolve the electric waves arrived through the optical rift with the help of prisms and optical screen. The hyperspectral sensor consists of one optic, one spectrograph and one digital cam. The two hyperspectral sensors are assembled in a house; therefore it is known ASIA DUAL system. The two cameras can perceive in the visible wavelength, near infrared range and short wave infrared range. The Eagle camera takes images in visible and near infrared range (VNIR), while Hawk operates in the middle infrared range (SWIR). By means of establishing of two cameras a DUAL system were installed. The full range is $400-2450 \mathrm{~nm}$, which can be set 1.25-10 nm wavelength band and maximum 498 spectral channels. Two sensors can also be operated separately, so it makes possible to utilize the wider wavelength of higher resolution (1024 pixels) VNIR sensor. Technical information of ASIA DUAL hyperspectral system:

- Push-broom hyperspectral imagery sensor with the fiber optic radiation meters (FODIS)

- Miniature integrated GPS/INS sensor, which serves the position, height and momentary situation (pith, roll, yaw) of plane

- Compact PC-based data collector and mobile receiver unit

- CaliGeo software runs as a separate software package under the ENVI software package to do the spectral and geometrical corrections.

The parameters of the hyperspectral image:

- Wavelength: 400-2450 nm (EAGLE: 400-970 nm and HAWK: 970-2450 nm)

- Spectral sample taking: 1,2-10 nm 
- Ground resolution: 0,4-3 m (with plane)

ENVI 4.7 software was applied for the analysis of hyperspectral images. Based on both the airborne and field reflectance measurements, vegetation idices were calculated. One of the vegetation indices is NDVI (Normalized Difference Vegetation Index) which shows high correlation to chlorophyll content (Burai et al., 2009). The NDVI was calculated by the $\mathrm{NDVI}=(\mathrm{NIR}-\mathrm{R}) /(\mathrm{NIR}+\mathrm{R})$ equation. The Water Band Index $(\mathrm{WBI})$ is also calculated. WBI is a reflectance measurement that is sensitive to changes in canopy water status. As the water content of vegetation canopies increase, the strength of the absorption around $970 \mathrm{~nm}$ increases relative to that of $900 \mathrm{~nm}$. WBI is defined by the following equitation: $\mathrm{WBI}=\delta_{900} / \delta_{970}$ (Champagne et al. 2001).

\section{Results and Discussion}

In the examined orchards, the airborne imaging system was used in fruit researches to develop a new GIS based recording system of fruit plantations and study the relationships between remotely-sensed indices and ground control measures of fruit trees. Based on field work unique data of all pear trees, registered in the genetic collection, were collected to one ESRI ARCGIS data base. Height measurements and digital photos of the trees were also carried out during the survey. Digital photos were taken of the fruits as well, although earlier taken photos of genetically typical, ripe fruits were set to the database. The pictures were geotagged to air photo based on coordinates.

Based on the results of the field measurements by ALTA II and the more detailed AvaSpec 2048 spectrometer, there was no significant correlation $(\mathrm{p}<0.05)$ between apple species cultivated by the same system. This is caused by the same planting date, cultivation method, site and climatic conditions. However there are significant differences was found between the integrated and bio cultivation. Differences in the NIR is the most remarkable (Figure 2.). This 
is caused by the stress effect of several bacterial and fungous disease (poedery and downy mildew, etc.), appeared on the leaves of apple trees of organic cultivation.

The characteristics of the reflectance curves of each fruit tree species are caused by the large amount of absorption of chlorophyll content at $450-670 \mathrm{~nm}$ wavelength intervals. On the other hand, reaching the near infra-red (NIR) interval the reflectance of the healthy apple and pear tree leaves are raising markedly at $700 \mathrm{~nm}$ (Figure 1.). Besides these, the reflectance value of the vegetation without any stress is high at NIR intervals, but low at red wavelength interval. Significant correlation $(\mathrm{R}=-0.705)$ between the chlorophyll contents and reflectance values was only found at $525 \mathrm{~nm}$-en wavelength in the case of ALTA measurements, which might be caused by the low spectral resolution. On the other hand there are significant correlation $(\mathrm{R}=-0.7--0.8)$ between the chlorophyll contents and reflectance values in the case of several wavelength of AVASPEC 2048 spectral curves due to the high spectral resolution $(1 \mathrm{~nm})$. Negative correlation is due to the high absorbance of the chlorophyll content. Based on these results the AVASPEC 2048 spectrometer was used for further field and laboratory studies in our experiment.

The leaf samples taken with R-Row/T-Tree positions in the study area were collected and analyzed on the basis of the field measured spectral curves. The Pearson correlation between chlorophyll and vegetation indices was carried out. Correlation between chlorophyll and Normalized Difference Vegetation Index (NDVI) was 0.8, between chlorophyll and Simple Ratio Index (SRI) was 0.54, between chlorophyll and Red Edge Position (REP) was -0.76 (Table 1).

The role of AvaSpec 2048 spectrometer in endmember (spectrum of clear phenomenon) determenination for further airborne hyperspectral image analysis was also studied. Beside stressed and not stress canopies the reflectance of other objects were also measured to elaborate the applicability of AvaSpec 2048 as a possible reference spectra collector gauge 
for AISA DUAL hiperspectral image. The field samplings were carried out paralell to the hiperspectral survey. Since the GPS coordinates of the field sampling point were collected, the coefficients of determination were calculated between the field collected spectra and airborne hyperspectral image at the specified pixels (Table 2). The the coefficients of determination and regression analysis between spectra were calculated by SPSS 14.0 software.

Based on the results strong, positive correlation and cubic regression were found between field and airborne spectra, thus the AvaSpec 2048 spectrometer is appropriate for endmember collection. The regression model was validated by paired $\mathrm{T}$ test. These endmember can be used for mapping of airborne hyperspectral images, thus the stressed and unstressed canopy can be mapped.

The n-dimensional hyperspectral image contained 359 channels. The bad bands, having bad signal/noise rate were excluded from further assessments. An image extract was taken form the hyperspectral image containing the extended environment of the apple plantation (Figure 3.). The picture shows the dissemination diagram prepared form the representative slice of the sample area. The spectral density space describes two channels between 653-751 nm. With the help of spectral cross-section we have the entities of apple orchard were examined with higher evaporation capability on the basis of relative reflectance values. The spectral profile of $961^{\text {st }}$ channel shows the crosswise distribution of the relative reflectance in one spectral channel. The projecting peaks mean the values of greater foliage (Figure 4.)

Further spectra were collected at several representative point of sample area in the cause of analyzing spectral curves. The smaller foliage trees are characterized by lower reflectance curves, while greater foliages are joint to higher and higher values among well separating curves on the spectral profile. The spectral profile shows the spectral value regarding to 1 
pixel $\left(2.25 \mathrm{~m}^{2}\right)$ as a function of foliage in case of all channels. On the picture it can be seen that the foliage separates marked in infrared range between 773-782 $\mathrm{nm}$ (Figure 5.).

Normalized Difference Vegetation Index (NDVI) was calculated as well, which shows close connection with chlorophyll content, with using near infrared (NIR: 730-1100 nm) and red (R: 580-680 nm) wavelength ranges. The value of the index is between -1 and 1 . In case of green vegetation the value of the index is $0.2-0.8$. The real value of the apple orchard in Pallag are the followings: $\min .=0.14 ; \max .=0.89$ (Figure 6.). Based on these results, trees with different biomass can be eliminated properly. The importance of this that the biomass strongly correlates to the transpiration of apple and pear trees thus the evapotranspiration can be determinable more precisely, which is important in irrigation management to avoid water stress.

The segmentation of the NDVI image was based on the GIS database of field measurements at the pear plantation. After vectorising the obtained segments, those pear species having different biomass weight were selected. Pixels covered by canopies of these trees, could be spectrally clear and unmixed. Although the results show, that real endmember pixels can only be found at trees having several canopy level and at least $1 \mathrm{~m}$ canopy diameter. Because of the replacement of necrotized trees the spectral properties of grass zone between rows can provide spectrally mixed values (as a $2^{\text {nd }}$ type errors of commission) due to the possible underdevelopement of trees. On the other hand, the spectral properties of neighboring trees can be mixed due to the overdeveloped tree canopy having more than $4 \mathrm{~m}$ diameter, which larger than the spacing in the row. Generally these errors of ommission $\left(1^{\text {st }}\right.$ type $)$ had minor role. The resulted, classified spectral data could be applied as a spectral library, which are suitable for the detailed examination of plant physiology and spectral data and water stress. The optimal climatic conditions for pear are generally cooler and humid, with at least $65 \%$ of 
relative air humidity. There is a lack of these conditions in Újfehértó at the 30-40\% in a year. At the examined site, pear species with large biomass concerned as those species which had major tolerance against drier and unfavourable environmental conditions. These genetic properties could be very important in the frame of the potential climate change. Stress, caused by the relative water lack, evolves in a short term physiological process. The first symptoms of water stress are often not visually observed, although those have negative effect on the yield quantity and quality. The conventional invasive measurements can hardly be reproduced, because of the sampling (cut) of the vegetation tissue (i.g. leaf, shoot) or only few $\mathrm{cm}^{2}$ of leaf area is measured, which limits the representative sampling. The airborne hyperspectral remote sensing data eliminate these disadvantages, since it can provide detailed spectral data from the whole canopy.

In Figure 7 the continuum removed spectra of Bajai, KörteB/3, Szentendrei császár, Vérteskozmai pear species are shown descending order of biomass. Continuum Removal is to normalize reflectance spectra to compare individual absorption features from a common baseline. The continuum is a convex hull fit over the top of a spectrum using straight-line segments that connect local spectra maxima. The first and last spectral data values are on the hull; therefore, the first and last bands in the output continuum-removed data file are equal to 1.0. The resulting image spectra are equal to 1.0 where the continuum and the spectra match, and less than 1.0 where absorption features occur.

Based on the horticultural data, the four biomass segments showed strong correlation with the water stress tolerance. The pear tree species were grafted to the same wild pear rootstock, thus there were no differences in the water consumption root zone. In accordance with the spectral data, the "Bajai" species produced large canopy with $5.7 \mathrm{~m}$ height and large yield quantity (Figure 8). 
The "Szentendrei császár" species grown on the same soil type, just some meters away from the presented "Bajai", has just $2 \mathrm{~m}$ height canopy and its yield is the one quarter of the "Bajai" one (Figure 9).

The stress was aslo assessed by WBI. According to our examinations as well, channel with $900 \mathrm{~nm}$ is found to be a sensitive water stress indicator, although the minimum value of the first derivative of the reflectance curve was at 930-940 nm wavelength interval. The $970 \mathrm{~nm}$ channel provided less usable values as a denominator for WBI (Figure 10).

Based on the abovementioned results, the reflectances of 886 and $937 \mathrm{~nm}$ can result more accurate WBI $\left(\mathrm{WBI}=\delta_{886} / \delta_{937}\right)$ in the case of pear trees. The spectral data also confirmed that the "Bajai" pear species can tolerate more the dry conditions of Újfehértó than the "Szentendrei császár" or the "Vérteskozmai" pear species.

\section{Conclusions}

Based on the results, the airborne hyperspectral remote sensing and field spectral measurements are very effective methods for surveying the vegetation. The climatic stress has an effect on vegetation. Species, grown in the concerned landscape had enhanced tolerance for harmful effects and water stress. The spectral library of the pear genetic collection in Újfehértó and the integrated GIS research database provide new opportunity to researchers and breeders in vegetation analysis. Due to this complex database and spectral library the effectiveness of understanding spectral anomalies and changing detection can be significantly increased.

\section{Acknowledgement}

This research was funded by OM-00265/2008 and OM-00270/2008 projects. 


\section{References}

Berke, J., D. Kelemen, and J. Szabó. 2004. Digitális képfeldolgozás és alkalmazásai. (Digital image processing and application) PICTRON Kft., Keszthely, Hungary

Burai, P., E. Kovács, Cs. Lénárt, A. Nagy, and I. Nagy. 2009. Quantification of vegetation stress based on hypersectral image processing. Cereal Research Communications. 37: 581584. Hungary

Champagne, C. A., E. Pattey, A. Bannari, and I.B. Stratchan. 2001. Mapping Crop Water Status: Issues of Scale in the Detection of Crop Water Stress Using Hyperspectral Indices. In Proceedings of the $8^{\text {th }}$ International Symposium on Physical Measurements and Signatures in Remote Sensing, edited by CNES, 79-84. Aussois. France.

Clark, R.N. 1999: Spectroscopy of rocks and minerals, and principles of spectroscopy. In Remote sensing for the earth sciences: Manual of remote sensing, ed. A. Rencz, 3-58. John Wiley and Sons, New York. USA.

Jolánkai M. 2010. Agriculture, soil management and climate change. In Climate change and Hungary: Mitigating the hazard and preparing for the impacts (The "VAHAVA" report), 3845. Budapest, Hungary.

Juhász. Cs. 2008. Vízgazdálkodás. (Watermanagement) In Tamás J. Agrárium és környezetgazdálkodás, ed. J. Tamás 218-220. Mezőgazda Kiadó. Budapest. Hungary

Kertész, Á. 1995. Aridification in a region adjacent to the Mediterranean. Objectives and outline of a scientific programme, Mediterranean Desertification and Land Use (MEDALUS) Working Paper 65. King's College. London. UK.

Kruse, F.A., J.W. Boardman, and J.F. Huntington. 2003. Comparison of airborne hyperspectral data and EO-1 hyperion for mineral mapping. Institute of Electrical and Electronics Engineers (IEEE) Transactions on Geoscience and Remote Sensing, 41(6): 13881400. USA. 
Milics, G., P. Burai, and Cs. Lénárt. 2008. Pre-Harvest Prediction of spring barley nitrogen content using hyperspectral imaging. Cereal Research Communications, Supplement: 18631866. Hungary

Polder, G., G.W. van der Heijden. 2001. Calibration and characterization of spectral imaging systems. In Multispectral and hyperspectral image acquisition and processing proceeding of The Society of Photo-Optical Instrumentation Engineers (SPIE) eds. Q. Tong, Y. Zhu and Z. Zhu 4548: 10-17. USA.

Sabins, F.F., 1997. Remote Sensing - Principles and Interpretation, 3rd ed., W.H. Freeman, New York, NY. USA.

Santoso, H., T. Gunawan, R.H. Jatmiko, W. Darmosarkoro, and B. Minasny. 2011. Mapping and identifying basal stem rot disease in oil palms in North Sumatra with QuickBird imagery. Precision Agriculture, 12(2): 233-248.

Soltész, M., Szabó, T.: 1998. Alma. (Apple) p. In: Gyümölcsfajta-ismeret és -használat. Ed. M. Soltész,:119-155. Mezőgazdasági Kiadó, Budapest. Hungary.

Várallyay, Gy.: 2002. The role of soil and soil management in drought mitigation. In: Proc. Int. Conf. On Drought Mitigation and Prevention of Land Desertification, Bled, Slovenia, April 21-25 2002. ICID-CIIC. (CD)

Várallyay, Gy.: 2007. Soil resilience (Is soil a renewable natural resource?). Cereal Research Communications 35. 1277-1280. Hungary. 


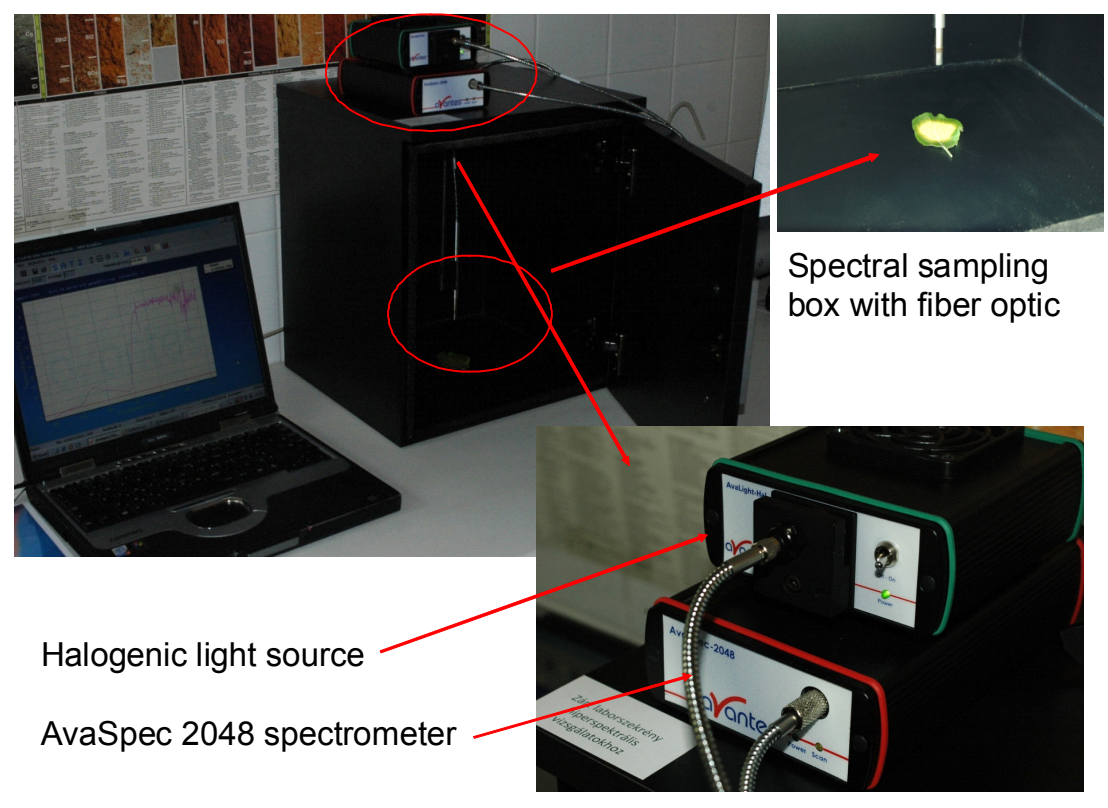

Figure 1. The AvaSpec 2048 spectrometer

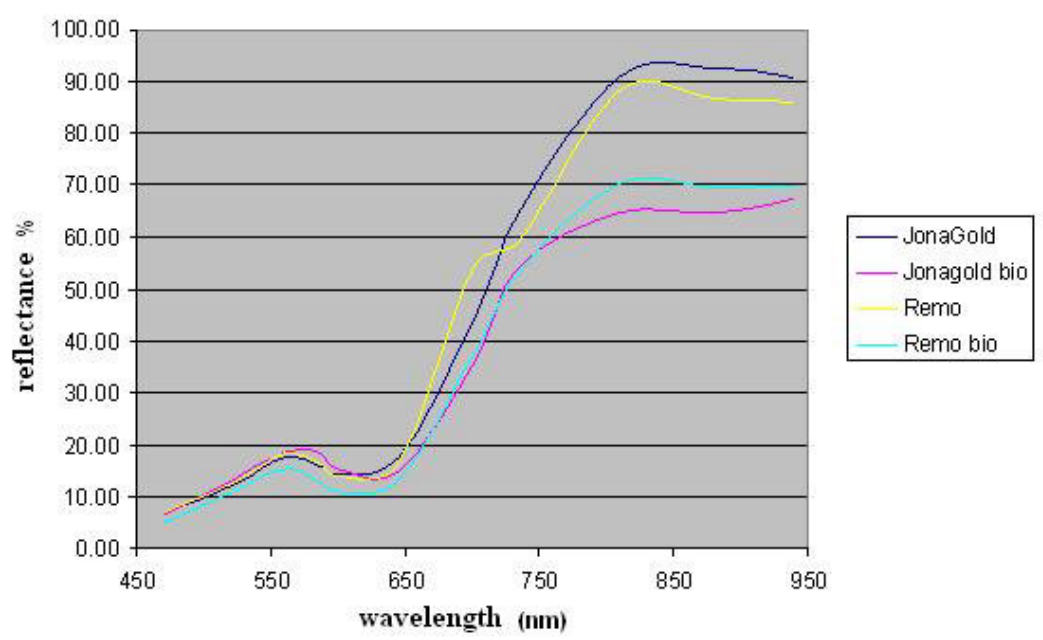

Figure 2. Spectral differences between Jonagold and Remo 


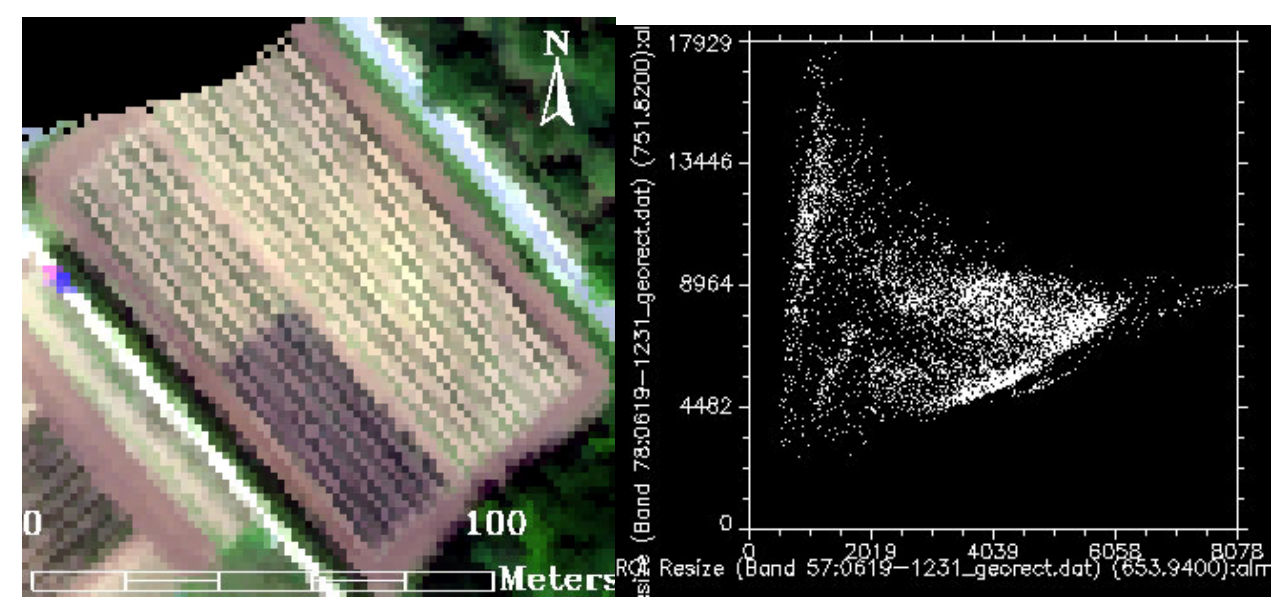

Figure 3. Apple orchard and the scatter plot of a RED and NIR channel



Figure 4. Spatial profile of the $963 \mathrm{~nm}$ channel in apple orchard

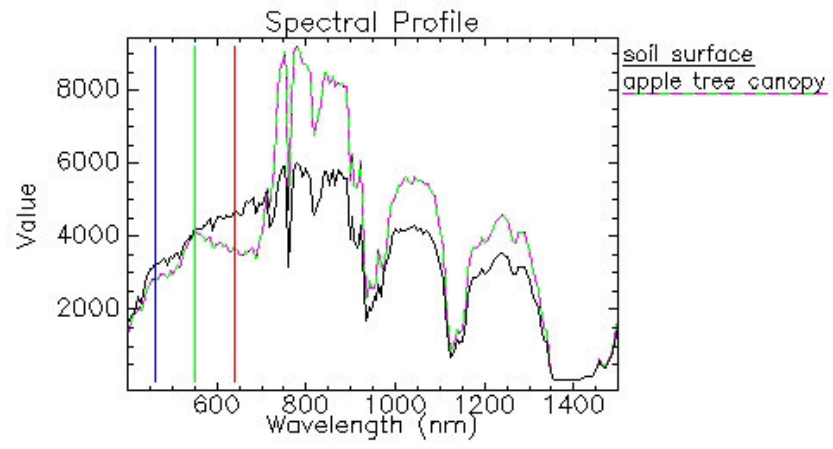

Figure 5. Spectral profile of soil and canopy 


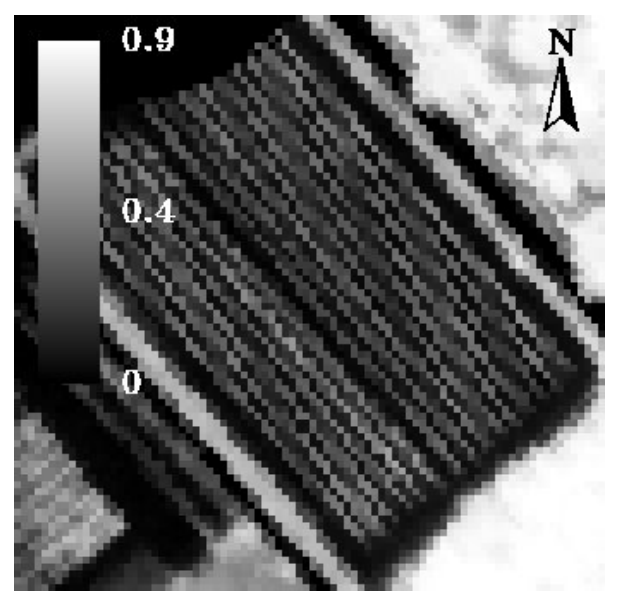

Figure 6. NDVI of the apple orchard

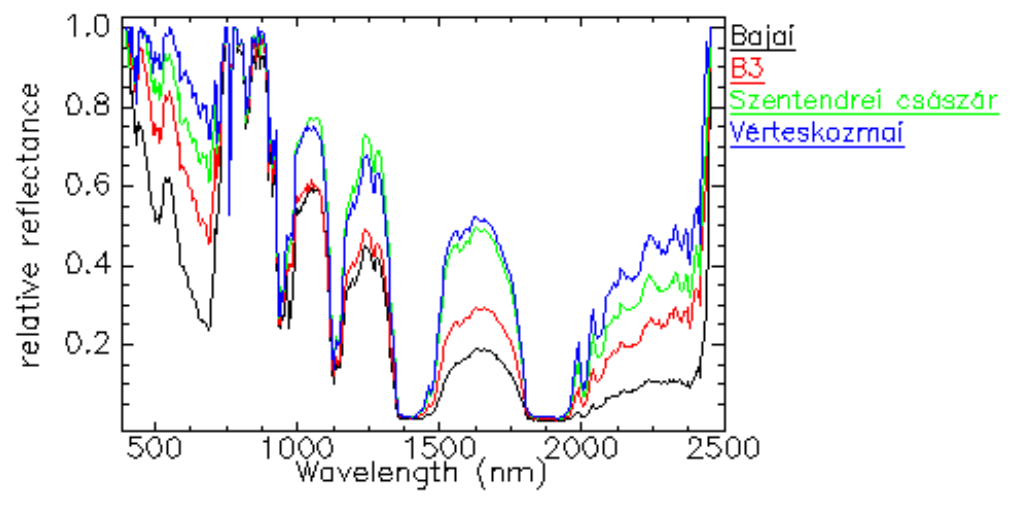

Figure 7. The pear species have species specific spectral properties

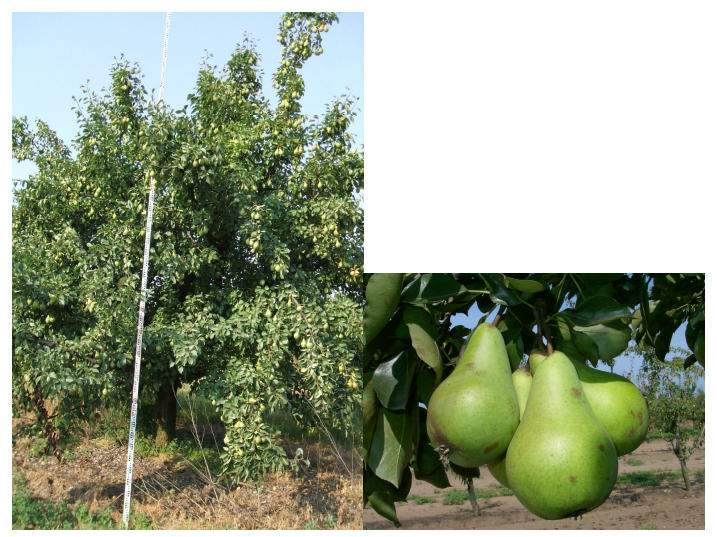

Figure 8. The water stress tolerable „Bajai” species 




Figure 9. The water stress sensitive "Szentendrei Császár” species

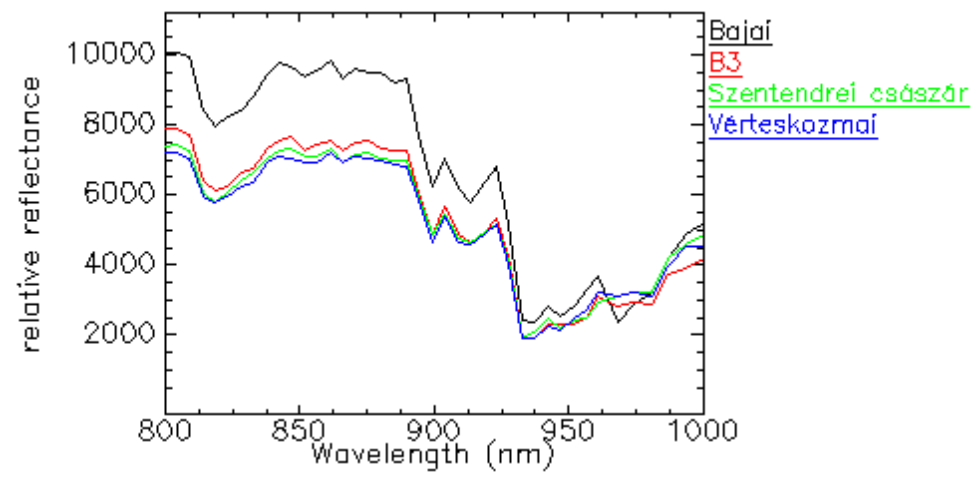

Figure 10. Spectral interval regarding water stress in the case of 4 pear species.

Table 1. Example for chlorophyll content and spectral indices

\begin{tabular}{|l|l|l|l|l|l|}
\hline Pear species & Row/Tree & NDVI* & SRI** & REP*** & $\mu \mathrm{g} / \mathrm{g}$ \\
\hline Napoca & $19 / 103$ & 0.62 & 4.96 & 718.4 & 883.52 \\
\hline Márianosztrai & $19 / 113$ & 0.41 & 4.95 & 720.7 & 509.12 \\
\hline Republica & $19 / 83$ & 0.58 & 3.39 & 712.1 & 982.72 \\
\hline Ananas & $19 / 79$ & 0.69 & 5.26 & 710.9 & 4522.88 \\
\hline
\end{tabular}




\begin{tabular}{|l|l|l|l|l|l|}
\hline Summer dean & $19 / 70$ & 0.67 & 4.84 & 712.9 & 3960 \\
\hline Kiev & $19 / 109$ & 0.489 & 2.79 & 721.7 & 407.36 \\
\hline
\end{tabular}

* Normalized Difference Vegetation Index

** Simple Ratio Index

*** Red Edge Position

Table 2. Relationship between c

\begin{tabular}{|l|l|}
\hline Objects & $\begin{array}{l}\text { Coefficient of } \\
\text { determination }\left(\mathrm{r}^{2}\right)\end{array}$ \\
\hline Farm road & 0.793 \\
\hline Fólia & 0.850 \\
\hline Stressed canopy & 0.949 \\
\hline Unstressed canopy & 0.954 \\
\hline Surplus water & 0.771 \\
\hline
\end{tabular}

